\title{
Leukemoid reaction in a patient with adenocarcinoma of the lung: a case report
}

\author{
Hendrik Riesenberg ${ }^{1 *}$, Frauke Müller $^{2}$ and Martin Görner ${ }^{2}$
}

\begin{abstract}
Introduction: Lung cancers are characterized by high incidence, prevalence and mortality. They may be associated with numerous paraneoplastic syndromes. Mild leukocytosis is not rare. The case described here, however, is of a female patient with adenocarcinoma of the lung who developed extreme leukocytosis at over 140,000 cells/ $\mathrm{LL}$. Descriptions of such leukemic forms of lung cancer are few and far between in the literature. In our case, the complete hematological diagnostic investigation, which included cytological, immunocytological, cytogenetic, histological and molecular genetic tests of the bone marrow (mutation analyses of $B C R-A B L$ and JAK2), was accompanied for the first time by a molecular genetic workup of the primary tumor for epidermal growth factor receptor and K-RAS gene mutations.
\end{abstract}

Case presentation: We present the medical case of a 51-year-old female Caucasian patient, who was diagnosed with a poorly differentiated stage IV (International Union Against Cancer staging) adenocarcinoma of the lung. While undergoing treatment, our patient developed extreme leukocytosis, for which, despite extensive diagnostic tests, no infection-related or hematological cause could be identified. The tumor proved to be highly resistant to treatment. Our patient died only five months after the initial diagnosis.

Conclusion: A leukemoid course can most likely be interpreted as the paraneoplastic production of hematopoietic growth factors. Despite the absence of a verified primary hematological origin, this possibility should always be investigated in all patients in a comparable situation.

\section{Introduction}

Both in Europe and in the US, lung cancer is by far the most common fatal cancer in both sexes [1,2]. The classic symptoms include coughing, dyspnea and hemoptysis. Particularly in small cell but also in nonsmall cell lung cancer, paraneoplastic syndromes are observed that, in terms of their characteristics and clinical relevance, should be classified very differently. The production of hormones or hormone precursors could result in endocrine paraneoplasia. Examples include the tumor-related production of parathyroid hormone, adrenocorticotropic hormone, antidiuretic hormone, thyroidstimulating hormone, insulin, erythropoietin, calcitonin and serotonin. These are distinct from antibodymediated paraneoplasia, which may result in unusual

\footnotetext{
* Correspondence: H.Riesenberg@uke.de

'Department of Oncology, Hematology and Bone Marrow Transplantation with Section of Pneumology, University Medical Center Hamburg-Eppendorf, Martinistraße 52, 20246 Hamburg, Germany

Full list of author information is available at the end of the article
}

skin changes (for example, dermatomyositis) but also in severe neurological disorders (for example, myasthenia, Lambert-Eaton syndrome).

It is not unusual for both small cell and non-small cell lung cancers to be associated with mild leukocytosis. These should be distinguished from the leukemoid courses of non-small cell lung cancer, especially large cell carcinoma, occasionally described in the literature, where the development of extreme leukocytosis at over 50,000 cells $/ \mu \mathrm{L}$ has been observed.

In the following case description, the origin of the leukemoid course is discussed in detail under both infection-related and hematological aspects, and explanations offered for the resistance to treatment. In addition, molecular genetic investigations of the primary tumor are presented for the first time.

\section{Case presentation}

We report on a 51-year-old female Caucasian patient with no significant previous illnesses. Our patient had

\section{Ciomed Central}


been a smoker for many years, with persistent nicotine use at the time of her first presentation. The initial symptom, which first led the patient to contact her primary care physician, was pain in the region of her left hip. She did not complain of cough, dyspnea, fever or night sweats. Her weight remained constant.

A computed tomography (CT) scan of her left hip joint demonstrated extensive osteolysis in the acetabulum with infiltration of the iliopsoas muscle. Moreover, bone fracture of the joint socket was highly suspected. Magnetic resonance tomography (MRT) of her pelvis confirmed the pathological fracture. Skeletal scintigraphy found no further evidence of osteolysis.

We performed a CT-guided biopsy of the large area of osteolysis in her left acetabulum. The histological diagnosis was of a poorly differentiated adenocarcinoma. Despite extensive immunohistological chemical analyses (pan-keratin focally positive; cytokeratin 8/18 moderately positive; cytokeratin $5 / 6$ weakly positive; cytokeratin 7 moderately to strongly positive; melanoma cocktail, thyroid transcription factor-1, mammaglobin, thyroglobulin, cluster of differentiation (CD) 56 and CD 138 negative), it proved impossible to assign the primary tumor to a particular organ.

Moderate leukocytosis at 21,200 cells/ $\mu \mathrm{L}$ was diagnosed as early as this point, in the presence of mild anemia and normal platelet concentration. No leukocyte differentiation was performed at this time. A routine blood count from one and a half years before, examined retrospectively for this analysis, was without pathological findings.

A CT scan of her neck, chest and abdomen and a MRT scan of her cranium were performed. These demonstrated a pulmonary tumor in her right hilar region with a diameter of $2.3 \mathrm{~cm}$, in close proximity to the upper lobe and encircling her right main bronchus (Figure 1). Enlarged lymph nodes up to $2.5 \mathrm{~cm}$ in size and infracarinal lymph nodes up to $2.0 \mathrm{~cm}$ in size were observed in her right hilar region. In addition, numerous pleural, pericardial and diaphragm metastases were diagnosed. No pulmonary metastases were seen. Excess tissue was shown in her right infraclavicular region. Abdominally, a distension of her left adrenal of $2.0 \mathrm{~cm}$ in diameter was assessed as highly suspect for metastasis. The cranial MRT findings were normal.

The leukocyte concentration in the mean time was elevated at 39,000 cells $/ \mu \mathrm{L}$, with largely unremarkable differentiation (see Table 1).

Bronchoscopy and transbronchial needle aspiration from her main and upper lobe carina demonstrated a moderately to poorly differentiated adenocarcinoma of the lung, consistent with the primary tumor of the known metastasis in her left acetabulum. In molecular pathological follow-up investigations, based on the

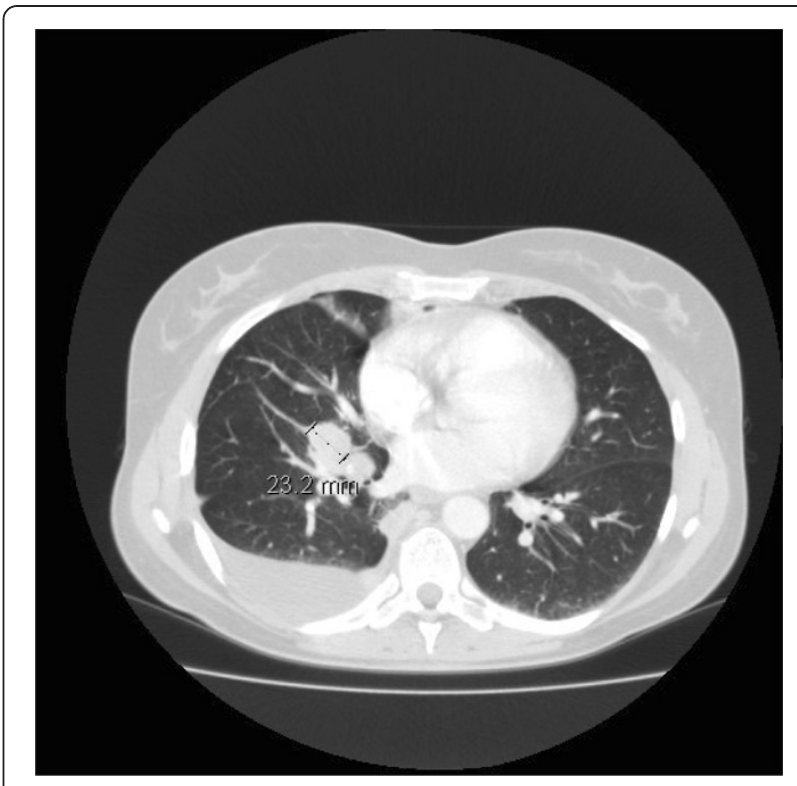

Figure 1 Primary lesion. Pulmonary tumor in the right hilar region with a diameter of $2.3 \mathrm{~cm}$ in close proximity to the upper lobe and encircling the right main bronchus.

metastasis of the acetabulum, no mutation of the epidermal growth factor receptor gene could be identified (wild type). The K-RAS gene exhibited a mutation, which argues in principle against the use of tyrosine kinase inhibitors of the gefitinib type.

The next step involved radiotherapy of the area of osteolysis in her left hip joint, including the surrounding soft tissue metastasis, of up to 40Gy with a single dose of 2Gy. In addition, simultaneous radio- and chemotherapy was started consisting of radiotherapy of the primary tumor and of the mediastinum up to $55.8 \mathrm{~Gy}$ with a single dose of $1.8 \mathrm{~Gy}$ plus cisplatin $\left(20 \mathrm{mg} / \mathrm{m}^{2}\right.$, days 1 to 4

Table 1 Blood count and infection parameters

\begin{tabular}{|c|c|c|c|c|}
\hline Serum concentration & $\begin{array}{l}29 \mathrm{Apr} \\
2008\end{array}$ & $\begin{array}{l}11 \text { Nov } \\
2010\end{array}$ & $\begin{array}{l}25 \text { Nov } \\
2010\end{array}$ & $\begin{array}{l}14 \text { Feb } \\
2011\end{array}$ \\
\hline Leukocytes (cells/ $\mu \mathrm{L})$ & 7900 & 21,200 & 39,000 & 146,200 \\
\hline Hemoglobin (g/dL) & 15.3 & 12.8 & 12.2 & 8.7 \\
\hline Platelets (cells/ $\mu \mathrm{L}$ ) & 249,000 & 337,000 & 372,000 & 266,000 \\
\hline Neutrophils (\%) & - & - & 92 & 85 \\
\hline Lymphocytes (\%) & - & - & 4 & 1 \\
\hline Monocytes (\%) & - & - & 3 & 2 \\
\hline Eosinophils (\%) & - & - & 0 & 0 \\
\hline Basophils (\%) & - & - & 1 & 1 \\
\hline Metamyelcytes (\%) & - & - & - & 6 \\
\hline Myelocytes (\%) & - & - & - & 5 \\
\hline $\begin{array}{l}\text { C-reactive protein } \\
(\mathrm{mg} / \mathrm{L})\end{array}$ & 2.8 & 19.5 & 43.2 & 49.3 \\
\hline Procalcitonin & - & - & - & 0.4 \\
\hline
\end{tabular}


and 29 to 32$)$ and vinorelbine $\left(12.5 \mathrm{mg} / \mathrm{m}^{2}\right.$, days $1,8,15$, 29, 36 and 43) was started.

In the course of the therapy, our patient reported progressive pain in the region of her left flank, which was attributable to a considerable increase in the size of the adrenal metastasis to $5.9 \times 4.4 \times 7.5 \mathrm{~cm}$. A blood count at this point showed leukocytosis at 146,200 cells/ $\mu \mathrm{L}$, with largely normal differentiation and complete maturation (Figure 2).

Inflammation parameters were, at most, mildly elevated (C-reactive protein $49.3 \mathrm{mg} / \mathrm{L}$, procalcitonin. 0.4). She had no fever, so we assumed not so much an inflammatory reaction or abscess formation but rather feared a hematological secondary disorder. Her levels of liver transaminases were normal (aspartate transaminase $17 \mathrm{U} / \mathrm{L}$, alanine transaminase $21 \mathrm{U} / \mathrm{L}$ ). A cytological bone marrow examination showed a massively increased and left-shifted granulopoiesis up to the myeloblasts with displaced erythropoiesis and normal megakaryopoiesis, as can typically develop under stimulation with granulocyte colony-stimulating factor (G-CSF) (Figure 3). In a fluorescence activated cell sorting analysis, granulocytic maturation of cells with partial coexpression of CD56 was predominantly seen. No immature cells were detected; in principle, these findings seemed consistent with the presence of myeloproliferative neoplasia.

Cytogenetic investigation showed a normal female chromosome set $(46, \mathrm{XX})$. Molecular genetic analysis by means of fluorescence in situ hybridization ruled out $\mathrm{t}(9 ; 22)$ translocation. As expected, polymerase chain reaction also failed to demonstrate a $B C R-A B L$ fusion gene. Similarly, a V617F mutation in the JAK2 gene could also not be demonstrated, which overall makes the presence of a myeloproliferative neoplasia very unlikely

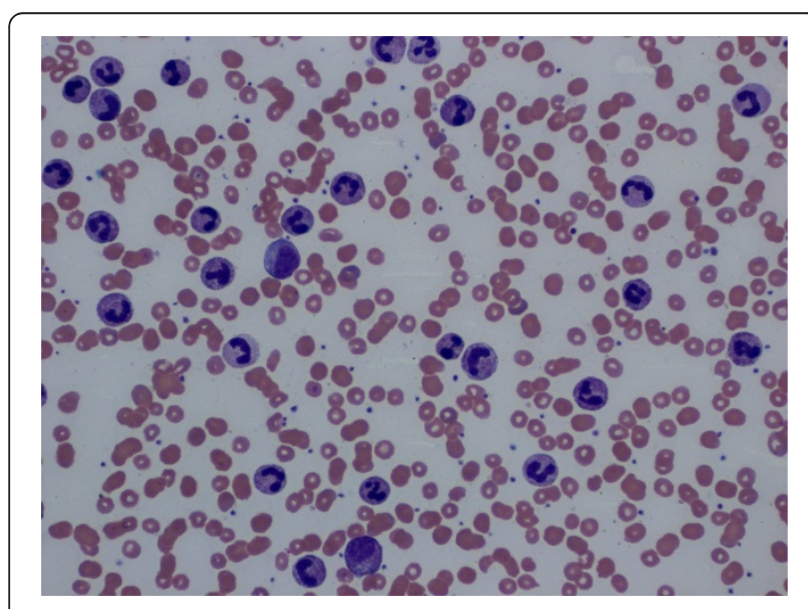

Figure 2 Peripheral blood smear. Extreme leukocytosis with largely normal differentiation and complete maturation (neutrophils $85 \%$, lymphocytes $1 \%$, monocytes $2 \%$, eosinophils $0 \%$, basophils $1 \%$, metamyelocytes $6 \%$, myelocytes $5 \%$ ).

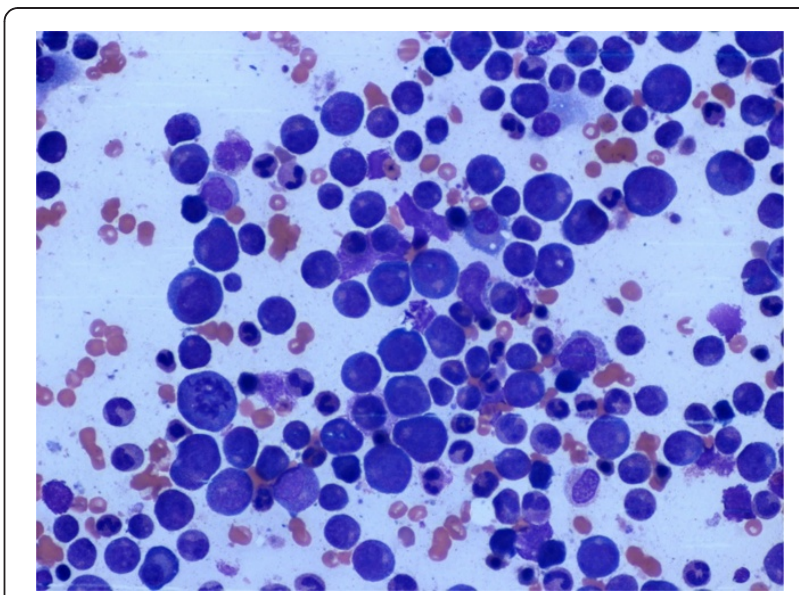

Figure 3 Bone marrow cytology. Massively increased and leftshifted granulopoiesis up to the myeloblasts with displaced erythropoiesis and normal megakaryopoiesis, as can typically develop on stimulation with granulocyte colony-stimulating factor (myeloblasts 4\%, promyelocytes 12\%, myelocytes 15\%, metamyelocytes $7 \%$, band cells $13 \%$, segmented neutrophils $31 \%$, proerythroblasts $2 \%$, erythroblasts $16 \%$, lymphocytes $2 \%$ ).

although it does not rule it out. On histology, a bone marrow biopsy also provided no evidence supporting either a hematological neoplasia, in particular chronic myelogenous leukemia. (CML), or the presence of infiltration by tumor cells.

Although our patient continued to exhibit no classic signs of inflammation, the differential diagnosis of abscess formation in the soft tissue metastasis in the iliopsoas muscle had to be followed up, given the absence of evidence for a hematological secondary disorder. However, this could not be confirmed by means of CT-guided biopsy. The biopsy specimen proved to be just as sterile as the repeatedly taken blood and urine cultures.

At the same time, the empirically initiated antibiotic treatment, first with ceftriaxone and subsequently with piperacillin and sulbactam sodium and also metronidazole, failed to affect either the leukocyte concentration or the C-reactive protein and procalcitonin to a clinically relevant degree.

Upon completion of the simultaneous radio- and chemotherapy, the primary tumor exhibited a slight regression. The adrenal metastasis, however, had increased in size during the ongoing therapy to $8.0 \times 4.8 \mathrm{~cm}$. We therefore attributed the regression of the primary tumor first and foremost to the radiotherapy and initiated systemic second-line therapy with docetaxel $\left(30 \mathrm{mg} / \mathrm{m}^{2}\right.$, once a week) and pemetrexed $\left(500 \mathrm{mg} / \mathrm{m}^{2}\right.$, repeated on day 22$)$. As there was no clinical response and our patient's general condition deteriorated continuously, this therapy was discontinued after just one cycle. A third-line therapy with gemcitabine $\left(1,000 \mathrm{mg} / \mathrm{m}^{2}\right.$, once a week) failed to have an effect either on the primary tumor or on the leukocyte concentration. 
Our patient died two weeks after starting the third-line therapy.

\section{Discussion}

Leukemoid courses of various tumor entities, especially gastrointestinal, urogenital, head-neck and lung cancers, have been described in the literature [3]. The development can be affected by a variety of factors. On the one hand, this may involve the presence of an infection or abscess formation. Equally, leukocytosis may be induced in the short term by the administration of high-dose corticosteroids. Another possible cause that needs to be considered is an existing or secondary hematological neoplasia, which develops following previous therapy $[4,5]$. The cause most discussed in the literature, however, is paraneoplastic production of hematopoietic growth factors. Asano et al. published the first report of CSF-producing lung cancers, characterized by the development of extreme neutrophilia. The neutrophilia was transferred to nude mice by the transplantation of tumor cells [6]. Likewise, several subsequent investigations demonstrated elevated serum concentrations of the hematopoietic growth factors G-CSF, granulocytemonocyte (GM)-CSF and also interleukin-6 in patients with lung cancer and extreme neutrophilia [7-9].

In an investigation published by Kasuga et al., out of 33 patients with tumor-associated leukocytosis (leukocytes from 11,400 cells/ $\mu \mathrm{L}$ to 190,000 cells $/ \mu \mathrm{L}$ ) and elevated serum concentration of various hematopoietic growth factors demonstrated by means of enzyme-linked immunoassay, only one patient exhibited small cell lung cancer. All the other patients exhibited non-small cell lung cancers, with the highest incidence being that of large cell carcinoma. In the case of the severe leukemoid courses (leukocytes $>50,000$ cells $/ \mu \mathrm{L}$ ), patients with large cell carcinoma also showed the highest incidence at $27.8 \%$, whereas leukocyte concentrations above 50,000 cells $/ \mu \mathrm{L}$ were demonstrated in just $0.8 \%$ of the identified adenocarcinomas and in $3.3 \%$ of the squamous epithelial carcinomas [10].

In a single case report on a patient with a leukemic course of a lung cancer, differentiation from CML was provided by a bone marrow biopsy; but no conclusions were reached on the precise histology of the primary tumor or with regard to molecular genetics [11].

As an example, we may refer here to the study by Shalom et al., which reports two patients (a 61-year-old woman with poorly differentiated large cell carcinoma and a 43-year-old man with poorly differentiated squamous epithelial carcinoma) in an extensively metastasized situation at the initial diagnosis, who, during the course of the illness, exhibited leukocyte concentrations exceeding 150,000 cells/ $\mu \mathrm{L}$ with the neutrophil granulocyte fraction exceeding $90 \%$. In both cases, neither the infection-related parameters nor the polymerase chain reaction for $B C R-A B L$ proved conclusive for ruling out CML. No further hematological investigations or analysis of the primary tumor were performed. Both patients failed to benefit at any time from their chemotherapy, and died only four and seven months after the initial diagnosis [12].

In the case described here, extensive diagnostic tests ruled out infection-related and primary hematological causes for the leukocytosis. A paraneoplastic origin seems likely. It is known that, to a high degree, epithelial tumors can express various forms of the G-CSF receptor and that cell proliferation may occur after ligand binding [13]. Paraneoplastic production of growth factors by the tumor itself would mean permanent stimulation of these tumor cells and explain the high aggressiveness and the uncontrollable progression. It is impossible to judge at this time if potential G-CSF and GM-CSF-stimulated signal transduction can be influenced by medication.

\section{Conclusions}

In rare cases, lung cancer can exhibit a leukemoid course. Where there is autonomous production of hematopoietic growth factors by the tumor cells themselves and concurrent, uncontrollable proliferation, the prognosis for such lung cancers is very poor. To distinguish between this paraneoplastic phenomenon and primary hematological or therapy-related secondary neoplasia, extensive hematological diagnostic tests should always be carried out.

\section{Consent}

Written informed consent was obtained from the patient's next of kin for publication of this case report and accompanying images. A copy of the written consent is available for review by the Editor-in-Chief of this journal.

\section{Competing interests}

The authors declare that they have no competing interests.

\section{Authors' contributions}

HR wrote the case report. HR and FM analyzed and interpreted the patient data relating to the oncological disease. MG analyzed and interpreted the patient data relating to the oncological disease and contributed to the writing and revision of the manuscript. All authors read and approved the final manuscript.

\section{Author details}

1 Department of Oncology, Hematology and Bone Marrow Transplantation with Section of Pneumology, University Medical Center Hamburg-Eppendorf, Martinistraße 52, 20246 Hamburg, Germany. ²Department of Hematology and Oncology, Community Hospital Bielefeld, Teutoburger Strasse 50, 33604 Bielefeld, Germany.

Received: 13 November 2011 Accepted: 1 May 2012

Published: 19 July 2012

\section{References}

1. Boyle P, Ferlay J: Cancer incidence and mortality in Europe, 2004. Ann Oncol 2005, 16:481-488. 
2. National Cancer I: Surveillance epidemiology and end results. http://seer. cancer.gov.

3. McKee LC Jr: Excess leukocytosis (leukemoid reactions) associated with malignant diseases. South Med J 1985, 78:1475-1482.

4. Griesinger F, Metz M, Trümpler L, Schulz T, Haase D: Secondary leukaemia after cure for locally advanced NSCLC: alkylating type secondary leukaemia after induction therapy with docetaxel and carboplatin for NSCLC IIIB. Lung Cancer 2004, 44:261-265.

5. Matsuo K, Kiura K, Tabata M, Uchida A, Hotta K, Niiya D, Kubonishi S, Ogino A, Fujiwara Y, Nakajima H, Shinagawa K, Ishimaru F, Ueoka H, Tanimoto M: Clustered incidence of acute promyelocytic leukemia during gefitinib treatment for non-small-cell lung cancer: experience at a single institution. Am J Hematol 2006, 81:349-354.

6. Asano S, Urabe A, Okabe T, Sato N, Kondo Y: Demonstration of granulopoietic factors in the plasma of nude mice transplanted with a human lung cancer and in the tumor tissue. Blood 1977, 49:845-852

7. Okabe T, Fujisawa M, Kudo H, Honma H, Ohsawa N, Takaku F: Establishment of a human colony-stimulating-factor-producing cell line from an undifferentiated large cell carcinoma of the lung. Cancer 1984, 54:1024-1029.

8. Katoh $Y$, Nakamura M, Ohnishi $Y$, Shimamura $K$, Ueyama $Y$, Tamaoki N: Autonomous production of granulocyte colony stimulating factor in tumor xenografts associate with leucocytosis. Br J Cancer 1993, 68:715-719.

9. Inoue M, Minami M, Fujii Y, Matsuda H, Shirakura R, Kido T: Granulocyte colony-stimulating factor and interleukin-6-producing lung cancer cell line, LCAM. J Surg Oncol 1997, 64:347-350.

10. Kasuga I, Makino S, Kiyokawa H, Katoh H, Ebihara Y, Ohyashiki K: Tumorrelated leukocytosis is linked with poor prognosis in patients with lung cancer. Cancer 2001, 92:2399-2405.

11. Salman T, Seker M, Bilici A, Basak-Oven Ustaalioglu B, Gurnus M, Yaylaci M: Lung cancer presenting with extreme leukocytosis. J BUON 2010, 15:193.

12. Shalom G, Sion-Vardy N, Dudnik J, Ariad S: Leukemoid reaction in lung cancer patients. Isr Med Assoc J 2010, 12:255-256.

13. Berdel WE, Danhauser-Riedl S, Steinhauser G, Winton EF: Various human hematopoietic growth factors (interleukin-3, GM-CSF, G-CSF) stimulate clonal growth of nonhematopoietic tumor cells. Blood 1989, 73:80-83.

doi:10.1186/1752-1947-6-211

Cite this article as: Riesenberg et al:: Leukemoid reaction in a patient with adenocarcinoma of the lung: a case report. Journal of Medical Case Reports 2012 6:211.

\section{Submit your next manuscript to BioMed Central and take full advantage of:}

- Convenient online submission

- Thorough peer review

- No space constraints or color figure charges

- Immediate publication on acceptance

- Inclusion in PubMed, CAS, Scopus and Google Scholar

- Research which is freely available for redistribution 